Department of Economics- FEA/USP

\title{
Exchange Rate Misalignment and Growth: A Myth?
}

\section{Carlos Eduardo GonÇalves MAURO RODRIGUES}

WORKING PAPER SERIES № 2017-07 


\title{
Exchange Rate Misalignment and Growth: A Myth?
}

\author{
Carlos Eduardo Gonçalves (cesg73@usp.br)
}

Mauro Rodrigues (mrodrigues@usp.br)

\begin{abstract}
:
The impact of real exchange rate movements on GDP growth is a hotly debated issue both in policy and academic circles. In this paper we provide evidence suggesting that there is not a robust statistical association between misalignment and growth for a broad panel of countries. Controlling for country fixed effects, time effects and initial GDP, a more depreciated currency is associated with higher growth. However, this positive association vanishes after controlling for the savings rate. We do not find such positive relationship either for large panel of countries or for a subsample of emerging economies.
\end{abstract}

Keywords: Real exchange rate; growth; misalignment.

JEL Codes: F31; F43; 047. 


\title{
Exchange Rate Misalignment and Growth: A Myth?
}

\author{
Carlos Eduardo Goncalves* $\quad$ Mauro Rodrigues ${ }^{\dagger}$
}

April 27, 2017

\begin{abstract}
The impact of real exchange rate movements on GDP growth is a hotly debated issue both in policy and academic circles. In this paper we provide evidence suggesting that there is not a robust statistical association between misalignment and growth for a broad panel of countries. Controlling for country fixed effects, time effects and initial GDP, a more depreciated currency is associated with higher growth. However, this positive association vanishes after controling for the savings rate. We do not find such positive relationship either for large panel of countries or for a subsample of emerging economies.
\end{abstract}

JEL Codes: F31, F43, O47

Keywords: Real exchange rate, growth, misalignment

*Affiliation: IMF and University of Sao Paulo, cgoncalves@imf.org

${ }^{\dagger}$ Associate Professor, Department of Economics, University of Sao Paulo, Brazil. Email: mrodrigues@usp.br. 


\section{Introduction}

In this paper we revisit the exchange rate-growth nexus using panel data estimations. Our findings go against the generally accepted view that a more depreciated exchange rate is conducive to higher growth rates.

In theory, the effect of deviations of the real exchange rate from its fundamental value on growth rates is ambiguous. In a model with learning by doing/scale economies, a depreciated currency can boost growth by temporarily shielding domestic producers from import competition, thus allowing them to travel up the production learning curve successfully. Additionally, if a depreciated currency leads to more investment in tradable sectors where long term productivity prospects are more promising, it could spark higher overall growth rates. On the other hand, if imported capital goods play a significant role in domestic capital formation, making them dearer through an undervalued currency may cause a fall in investment and growth rates.

It is a priori hard to say which effect should prevail, and thus going empirical is crucial. Rodrik (2008) is a major reference in the empirical literature dealing with this question. Using data from 1950 to 2004 from Penn World Table (PWT 6.2), he finds that a measure of exchange rate misalignment is indeed associated with GDP per capita growth rates: undervalued currencies leading to higher growth rates, and overvalued currencies to lower growth rates. The author claims this effect is due to currency misalignments in emerging economies (no significant effect for advanced economies).

Here we use the same methodology, but employ data from the latest version of the Penn World Table (PWT 9.0). For a broad panel of countries, we show that the relationship between real exchange rate deviations and growth vanishes after controlling for an important omitted 
variable: the savings rate. In a world with imperfect capital markets, internal savings may matter for growth. For instance, in Aghion et al (2016) model, domestic savings increase the attractiveness of FDI which boosts growth ${ }^{1}$. At the same time, though, higher savings are associated with smaller current account deficits and thus with a less depreciated exchange rate. This implies a positive association between misalignment and growth may simply reflect these two variables' correlation with savings.

There is large body of research investigating the growth effects of exchange rates. Some papers emphasize the deleterious effects of overvaluation (Sachs and Warner, 1995; Razin and Collins, 1997; Easterly, 2005; Rajan and Subramanian, 2011). Rodrik (2008), however, finds evidence that not only overvaluation is bad for growth, but also that an undervalued currency tends to spur growth.

Using a large panel of countries, he proceeds in two stages. In the first stage, he regresses real exchange rate against per capita income and time fixed effects. Residuals from this regression are then taken as a measure of undervaluation of the local currency. In the second stage, he regresses GDP per capita growth against the undervaluation variable and other controls. Here we follow the same methodology, but use more recent data (1950 to 2014). Furthermore, we emphasize the role of savings as a possible confounder in the estimation of the undervaluationgrowth relationship.

Other papers follow this strategy, reaching similar results. Berg and Miao (2010) control for other possible determinants of the real exchange rate in the first stage. As in Rodrik, they find evidence that first-stage residuals are highly correlated with GDP per capita growth. Gluzman,

\footnotetext{
${ }^{1}$ The logic is that foreign ownership is better protected from expropriation if the company has a domestic partner: for political economy reasons, the sovereign is less likely to expropriate domestic players, attenuating the agency problem and rendering FDI flows safer.
} 
Levy-Yeyati and Sturzenegger (2012) show that the growth effects of an undervalued currency work through savings, investment and employment. Levy-Yeyati, Sturzenegger and Gluzman (2013) find evidence that countries intervene to avoid overvaluation, and these interventions are related to faster growth. Arguably, these effects are particularly strong for developing economies.

We however find no evidence that an undervalued currency is related to higher growth. In our full panel (which includes developed and developing countries), the effect of undervaluation on growth is positive, but becomes statistically insignificant and its magnitude is substantially reduced once we add savings as a control. More importantly, we do not find evidence that the effect is stronger for a subsample of emerging economies, contrarily to Rodrik's findings. In all our specifications, once we control for savings, the estimated effect of exchange rate deviations becomes statistically insignificant.

The rest of the paper is organized as follows: section 2 lays down the methodology used, section 3 presents the estimates and section 4 briefly concludes.

\section{Data and methodology}

For our benchmark estimations we rely on data from the latest version of the Penn World Table (PWT 9.0), which encompasses the period between 1950 and 2014. We consider 13 five-year periods: 1950-54, 1954-60, .., 2010-14. Unless otherwise noted, variables refer to averages across each period.

Estimation proceeds in two stages. In the first stage we regress the real exchange rate (local currency/USD) on a set of time dummies and on GDP per capita levels. As in Rodrik (2008), the idea is to control for Balassa-Samuelson type of effects and global macro shocks. 


$$
\ln R E R_{i t}=a+b \cdot \ln Y_{i t}+\gamma_{t}+e_{i t}
$$

where $R E R_{i t}$ is country $i$ 's average real exchange rate over period $t, Y_{i t}$ is country $i$ 's average real GDP per capita over period $t$, and $\gamma_{t}$ are time fixed effects. We then compute a measure of deviations/misalignments, which are the residuals of the equation above. We call this variable $D e v_{-} R E R_{i t}$.

The second stage is a stripped-down version of a Barro growth regression with exchange rate deviations entering as a regressor:

$$
g_{i t}=\alpha+\beta . \ln Y_{i t}^{0}+\delta . \text { Dev_RER }_{i t}+\theta . \text { Savings }_{i t}+\mu_{i}+\gamma_{t}+\varepsilon_{i t}
$$

where $g_{i t}$ is the average annual growth rate of GDP per capita in period $t$, country $i$; $Y_{i t}^{0}$ is the initial GDP per capita of country $i$, period $t ;{ }^{2} \mu_{i}$ and $\gamma_{t}$ are, respectively, country and time fixed effects. We include $\ln Y_{i t}^{0}$ to capture standard convergence effects. Moreover, Savingsit is country $i$ 's average savings rate over period $t$, defined as one minus the shares of private consumption and government consumption in GDP. We run regressions with and without the savings rate as a control.

Savings are a possible confounding factor in estimating the exchange rate-growth relationship. Higher savings can both boost growth and contribute to a more devalued currency at the same time. As shown below, savings and exchange rate deviations are indeed strongly correlated. Furthermore, the inclusion of savings reduces substantially the magnitude and precision of the estimated effect of undervaluation on growth.

\footnotetext{
${ }^{2} Y_{i t}^{0}$ is real GDP per capita of country $i$ in the first year of period $t$.
} 


\section{Estimations}

\subsection{First-stage estimations}

Using data from the latest version of the PWT we estimate:

$$
\begin{aligned}
\ln R E R_{i t} & =\underset{(34.17)^{* * *}}{3.778}-\underset{(-16.95)^{* * *}}{0.187} \ln Y_{i t} \\
N & =1899, \quad R^{2}=0.456
\end{aligned}
$$

where values in parenthesis are robust t-statistics (the regression includes a full set of time dummies). Our results are very similar to Rodrik's. GDP per capita is negatively associated with the log-levels of the exchange rate, meaning more developed economies tend to have stronger currencies. This is the famous Balassa-Samuelson effect: higher productivity in the tradable sector increases wages in both tradable and non-tradable sectors, which in turn put a pressure on non-tradable prices leading to a stronger currency. The statistical significance of this variable, as in Rodrik, is very high.

Table 1 displays descriptive statistics on our main variables. We show separate statistics for emerging economies, which we define as countries with GDP per capita smaller than $70 \%$ of that of the US and larger than USD 1,000 (data from very poor countries are in general less reliable). 
Table 1: Descriptive statistics

\begin{tabular}{lccc|ccc}
\hline \hline & \multicolumn{3}{c|}{ All countries } & \multicolumn{3}{c}{ Emerging economies } \\
\hline & Mean & Std. Dev. & $N$ & Mean & Std. Dev. & $N$ \\
\hline Growth & 0.023 & 0.096 & 1899 & 0.024 & 0.099 & 1401 \\
RER deviation & 0.000 & 0.454 & 1899 & 0.067 & 0.401 & 1401 \\
Savings & 0.153 & 0.270 & 1899 & 0.140 & 0.251 & 1401 \\
\hline \hline
\end{tabular}

We have argued above that savings and real exchange rate deviations are likely positively correlated. Therefore, the effect of undervaluation on growth would be biased upward if savings were excluded in exchange rate-growth regressions. In our sample, this correlation is indeed positive and highly significant. Table 2 reports the outputs of panel regressions of RER deviations against savings (full sets of country and time fixed included). We present results for our full sample of countries and for the subsample of emerging economies. In both cases the coefficient of savings is positive and highly significant. 


\section{Table 2: Correlation between RER deviations and savings}

\begin{tabular}{lcc}
\multicolumn{2}{c}{ Dependent variable: RER deviations } \\
\hline \hline & All countries & Emerging economies \\
\hline Savings $_{i t}$ & $0.559^{* * *}$ & $0.477^{* * *}$ \\
& $(4.84)$ & $(3.82)$ \\
$N$ & & 1401 \\
$\#$ countries & 1899 & 166 \\
R-squared & 0.140 & 0.123 \\
\hline \hline
\end{tabular}

Numbers in parentheses are robust t-stats. ${ }^{* * *} \mathrm{p}<0.01,{ }^{*} \mathrm{p}<0.05,{ }^{*} \mathrm{p}<0.1$.

\subsection{Second stage estimations}

We next report second-stage results (see Table 3). The dependent variable now is the average annual growth rate multiplied by 100. Column (1) exhibits results for the whole sample, which combines both developed and developing countries. In addition to the deviation variable, we include the log of initial GDP per capita plus time and country fixed effects. Using this specification, we find a significant effect of exchange rate deviations on growth (see column (1)). The magnitude is large, although somewhat smaller than the one reported by Rodrik (in a similar regression his coefficient of Dev_RER is around 1.7, compared to 1.3 found here). A one standard deviation increase in this variable is associated to a growth rate higher by $1.318 \times 0.454 \approx 0.60$ percentage points. This is a big number, given mean growth rate in the sample is $2.3 \%$.

However - and this is the main message from this paper - when we include savings in our regression (column (2)), the estimated effect of Dev_RER becomes insignificant, with the 
magnitude of the point estimate being cut in half.

We repeat the analysis in column (3) and (4), now removing outliers. ${ }^{3}$ This time, the coefficient of RER deviation is insignificant even when we do not control for savings. Moreover, the effect of savings is now large and very precisely estimated. For each percentage point increase in this variable, we find a positive of impact of 0.1 percentage points in the average growth rate.

Columns (5)-(8) are analogous to columns (1)-(4), but restrict the sample to emerging economies only. Results are broadly similar. Importantly, we do not find stronger growth effects of devaluations for this group of countries. In some specifications (as in columns (5) and (6)), the estimated coefficients of Dev_RER are actually smaller than those found for the full sample. In any case, when we control for savings, the effect of devaluations becomes insignificant once again. This stands in sharp contrast with Rodrik's finding that devaluations have stronger growth effects in emerging economies.

\footnotetext{
${ }^{3}$ We remove, as outliers, country-period pairs that displayed: (i) average GDP per capita growth rates larger than 10 or smaller that -5 ; or (ii) average devaluations rates smaller than -5 or larger than 5 ; or (iii) average savings rates smaller than zero or larger than 1 .
} 


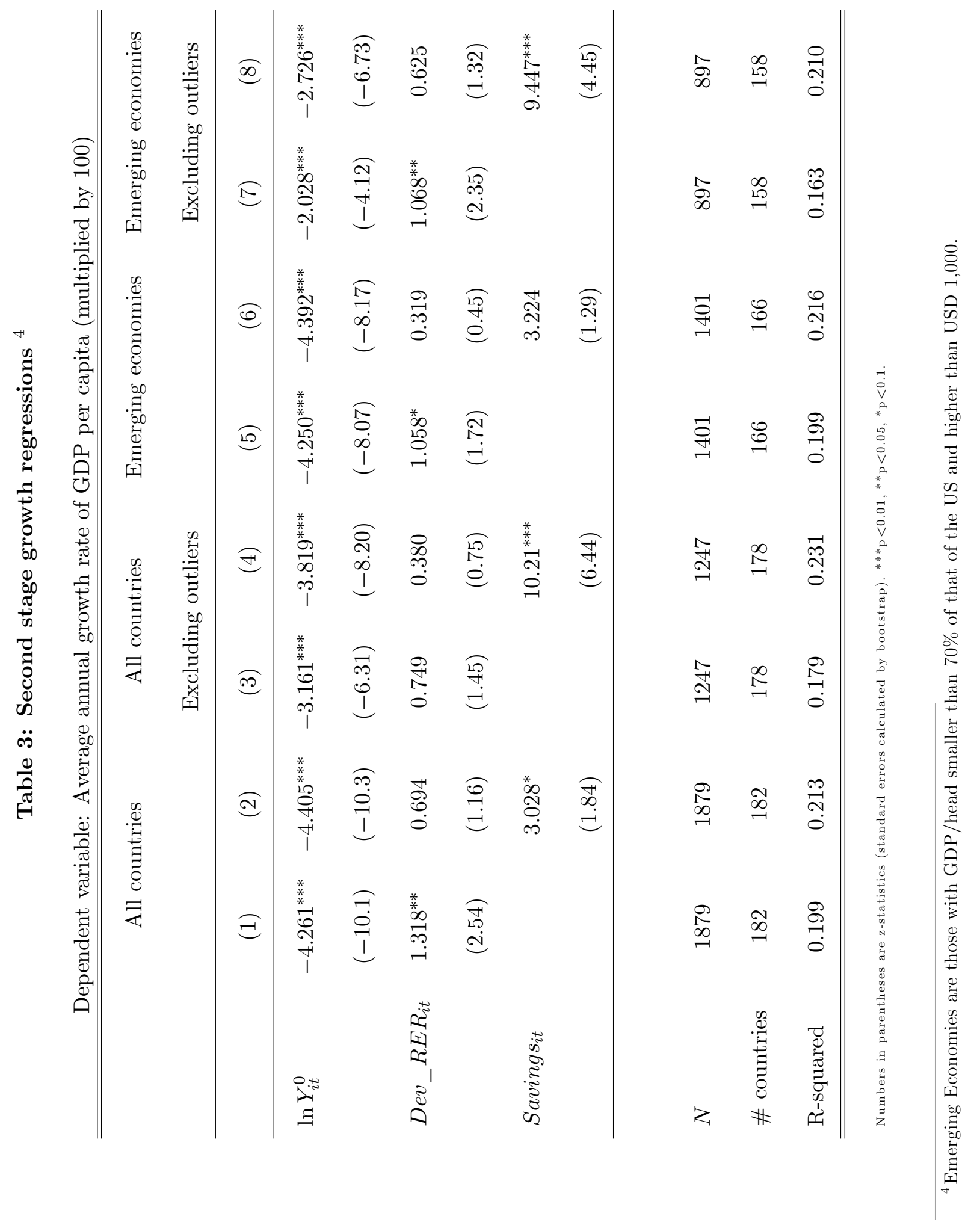




\subsection{Overvaluations versus Undervaluations}

Linearity may be a strong assumption: overvaluations can be fundamentally different from undervaluations in terms of growth impacts - as mentioned, many papers investigate the deleterious effects of RER overvaluations on growth. To assess the importance of this kind of asymmetric effect, we estimate the following specification:

$$
g_{i t}=\alpha+\beta \cdot \ln Y_{i t}^{0}+\delta . D e v_{-} R E R_{i t}+\eta \cdot P_{i t} \times D e v_{-} R E R_{i t}+\theta \cdot \text { Savings }_{i t}+\mu_{i}+\gamma_{t}+\varepsilon_{i t}
$$

where $P_{i t}$ is equal to 1 if $D e v_{-} R E R_{i t} \geq 0$ (i.e., currency is undervalued), and equal to zero otherwise (overvalued currency).

Now the marginal impact of an overvalued currency is captured by coefficient $\delta$, whereas the impact of an undervalued currency is given by $\delta+\eta$. Table 4 displays the results of this exercise. We only show regressions that include savings as a control variable. For our full sample of countries, the coefficients of both $D e v_{-} R E R$ and the interaction variable are statistically insignificant (columns (1) and (2) below). In other words, we find neither evidence that undervaluations are good for growth, nor that overvaluations are bad growth.

Columns (3) and (4) report the same estimations for our sample of emerging economies. In column (3) we actually see a positive impact of overvaluations on growth $(\delta>0)$ and negative impact of undervaluations on growth $(\delta+\eta<0)$. However, these coefficients may capture the fact that crisis periods in emerging markets are both characterized by low growth and capital flight (giving rise to undervaluations); and in large expansions we should observe the opposite. Indeed, when we exclude outliers (in particular, very large overvaluations and undervaluations), the coefficients of Dev_RER $R_{i t}$ and $P_{i t} \times D e v_{-} R E R_{i t}$ become once again insignificant (see 
column (4)).

\section{Table 4: Second stage growth regressions}

Dependent variable: Average annual growth rate of GDP per capita (multiplied by 100)

\begin{tabular}{|c|c|c|c|c|}
\hline & \multicolumn{2}{|c|}{ All countries } & \multicolumn{2}{|c|}{ Emerging economies } \\
\hline & (1) & $(2)$ & $(3)$ & $(4)$ \\
\hline \multirow[t]{2}{*}{$\ln Y_{i t}^{0}$} & $-4.389^{* * *}$ & $-3.834^{* * *}$ & $-4.321^{* * *}$ & $-2.728^{* * *}$ \\
\hline & $(10.27)$ & $(-8.19)$ & $(8.08)$ & $(-6.67)$ \\
\hline \multirow[t]{2}{*}{$D e v_{-} R E R_{i t}$} & 0.889 & 0.015 & $1.944^{*}$ & 0.557 \\
\hline & $(1.20)$ & $(0.02)$ & $(1.76)$ & $(0.66)$ \\
\hline \multirow[t]{2}{*}{$P_{i t} \times D e v_{-} R E R_{i t}$} & -0.449 & 0.786 & $-3.184^{* *}$ & 0.120 \\
\hline & $(-0.31)$ & $(0.66)$ & $(-2.06)$ & $(0.09)$ \\
\hline \multirow[t]{2}{*}{ Savings $_{i t}$} & $2.959^{*}$ & $10.16^{* * *}$ & 2.683 & $9.446^{* * *}$ \\
\hline & $(1.78)$ & $(6.41)$ & $(1.06)$ & $(4.44)$ \\
\hline Outliers excluded & No & Yes & No & Yes \\
\hline$N$ & 1879 & 1247 & 1401 & 897 \\
\hline \#countries & 182 & 178 & 166 & 158 \\
\hline R-squared & 0.213 & 0.232 & 0.220 & 0.210 \\
\hline
\end{tabular}

Numbers in parentheses are z-statistics (standard errors calculated by bootstrap). $* * * \mathrm{p}<0.01, * * \mathrm{p}<0.05, * \mathrm{p}<0.1$. 


\section{Concluding remarks}

In this short paper we investigate the impact of real exchange rate misalignments on growth. We follow closely Rodrik (2008), which finds evidence that a depreciated real exchange rate tends to boost growth, based on a panel of countries. His results are particularly strong for a subsample of developing economies.

Here we use a more recent version of PWT data, while emphasizing the importance of controlling for domestic savings. The exclusion of this variable may bias upward the effect of the real exchange rate, since higher savings can both increase growth and contribute to a more depreciated currency. Indeed, in our sample, RER deviations and savings are strongly correlated.

For a broad panel of countries, we do find that RER deviations are positively associated with growth. However, this effect becomes statistically insignificant when we include savings as a regressor. This also holds true for a subsample of emerging economies. We also estimate an alternative specification which allows for different effects of undervaluations and overvaluations on growth. We do not find robust growth effects in either case.

To summarize, contrarily to Rodrik's famous result, we do not find evidence that RER misalingments matter for growth, either for a broad set of countries or for a subsample of emerging economies.

\section{References}

[1] Aghion, P.; Comin, D.; Howitt, P.; Tecu, I. 2016. "When do domestic savings matter for growth?" IMF Economic Review 3: 381-407. 
[2] Berg, A.; Miao, Y. 2010. "The Real Exchange Rate and Growth Revisited; The Washington Consensus Strikes Back?" IMF Working Paper \#10/58, International Monetary Fund.

[3] Easterly, W. 2005. "National Policies and Economic Growth: A Reappraisal." In: Aghion, P.; Durlauf, S. (ed.). Handbook of Economic Growth, volume 1, chapter 15, p. 1015-1059.

[4] Gluzmann, P. A.; Levy-Yeyati, E.; Sturzenegger, F. 2012. "Exchange rate undervaluation and economic growth: Díaz Alejandro (1965) revisited." Economics Letters 117(3): 666-672.

[5] Levy-Yeyati, E.; Sturzenegger, F.; Gluzmann, P. A. 2013. "Fear of appreciation." Journal of Development Economics 101(C): 233-247.

[6] Rajan, R. G.; Subramanian, A. 2011. "Aid, Dutch disease, and manufacturing growth." Journal of Development Economics 94(1): 106-118.

[7] Razin, O.; Collins, S. M. 1997. "Real Exchange Rate Misalignments and Growth." NBER Working Paper \#6174.

[8] Rodrik, D. 2008. "The Real Exchange Rate and Economic Growth." Brookings Papers on Economic Activity 39(2): 365-439.

[9] Sachs, J. D.; Warner, A. 1995. "Economic Reform and the Process of Global Integration." Brookings Papers on Economic Activity 26(1): 1-118. 